\title{
The Influence of Two \\ Different Learning Approach on Oncology Nursing Education
}

Indonesian Nursing Journal of Education and Clinic (INJEC)

II6-124

Volume 5, Issue 2, December 2020

DOI: I0.24990/injec.v5i2.300

injec.aipni-ainec.org/index.php/INJEC/index

Received : 2020-05-26

Accepted : 2020-06-28

The Association of Indonesian Nurse

Education Center (AINEC)

\author{
Neșe Uysal '®D, Ayșegül Koç '
}

\begin{abstract}
Introduction: : Innovative education activities contribute to the professional development of students. This research is aimed to determine the influence of constructivist learning-based practices on nursing students' knowledge levels of cancer and cancer nursing functions and problem solving ability.

Methods: In the study, a quasi- experimental design with pretest-posttest control group was used. The second-grade nursing department students, who had oncology nursing lessons, were included in the study. A total of $8 I$ students were divided into three groups: constructivist methods $(n=3 \mid)$, clinical practice $(n=2 I)$ and control group $(n=29)$. The students in the constructivist approach group had four weeks of constructivist education while the students in the clinical practice group practiced in the oncology clinics. Research data were collected using information form, cancer nursing knowledge test and problem solving inventory. Mean values, Kruskal Wallis Test, and Wilcoxon sign test were used to evaluate the data.

Results: There was a statistically significant difference in the posttest scores of the groups $(K W=$ 4.79; $p \leq 0.00 \mathrm{I}$ ). A significant difference was found between the knowledge pretest scores and posttest scores of the students in the constructive method group $(Z=-4.84 ; p \leq 0.00 I)$. There was no statistically significant difference in problem solving skills in the posttest scores of the groups $(K W=0.33 ; p \geq 0.05)$. Conclusion: As a result of the research, it was determined that constructivist learning approaches positively affect oncology nursing knowledge test score. It is suggested to use innovative methods in the teaching and learning process of nursing practice.
\end{abstract}

\section{Keywords}

cancer nursing; constructivist; education; learning

\section{INTRODUCTION}

Oncology nurses have important roles and responsibilities, such as patient evaluation, patient education, care coordination, symptom management and supportive care. Oncology nurses who take part in every stage of the disease process, such as diagnosis, treatment and rehabilitation, actively take part in the critical decision-making process as well as in intensive care and treatment applications and provide team coordination (Rieger and Yarbro, 2003; Quinn, 2008; Bahrami, 2010). The fact

\footnotetext{
' Department of Nursing, Faculty of Health Science, Yıldırım Beyazıt University

Corresponding Author:

Neșe Uysal, Department of Nursing, Faculty of Health Science, Amasya University, Ipekköy, Amasya, Turkey Amasya University, Akbilek Mahallesi, Hakimiyet Cd. No:4/3, 16160 Merkez/Amasya, Turkey Email: uysaln2007@hotmail.com
} 
that oncology nursing is a special quality and complex discipline, fulfilling important responsibilities, and the increase in oncology cases reveal the growing need for this area. For these reasons, it is important to increase nursing students' knowledge, skills and awareness levels about oncology nursing during their undergraduate education (Komprood, 2013; Gill, and Duffy, 20I0).

Education aims to prepare new generations and to give them the ability to solve problems for the future (Bush, 2006). One of the most important goals of today's modern education approaches is to educate individuals who do not memorize the knowledge conveyed to them, who interpret the knowledge, synthesize it and produce new information. Within this scope, the education process is a dynamic approach that teaches learning. It is stated that learning environments, learning strategies and the choice of methods to be used in learning and the measurement tools to be used should be considered within this scope (Hawk and Shah, 2007). One of the innovative approaches that can be used in education is constructivist learning. According to this approach, the student is at the center of the teaching process. This approach, which regards learning as a mental process, emphasizes that individuals need to learn more, understand, be responsible for their own learning, and learn to control their own behavior. In a constructivist approach, critical thinking, questioning, problem solving and entrepreneurship of the individual are featured. In this learning style, there are applications such as research and project preparation, making simulations or role studies, creating multiple learning environments, making case studies, and creating questioning-based discussion environments (Brooks and Brooks, 1999). Another of the approaches of experiential learning is to build knowledge using real-life experiences. Learning does not only change with increasing experience, the previous experiences influence students' approach to new experiences and, consequently, change their ability to learn differently. Students will have the opportunity to apply their knowledge in real life. The use of experiential teaching approaches in nursing education increases the ability of nursing students to provide holistic care and to make accurate clinical decisions in a short time in the face of complex and complicated situations (Yardley et al. 20I2; Nielsen et al. 2013; Theisen and Sandau 20I3).

In the literature, it is suggested that the content of education in oncology nursing is to be based on real experiences, contains instructive information and clinical experiences, and to be regulated by developing innovative strategies rather than the perception about the complexity of oncology nursing (Komprood, 20I3). It is suggested that, in the models of education that embrace lifelong learning, students should work with appropriate role model nurses and that experiential learning methods should be used to improve their competence (Gill and Duffy, 2010; Komprood, 2013). The course load for oncology nursing is insufficient in undergraduate education in Turkey and likewise the working possibilities with mentor oncology nurses and practicing possibilities in oncology services for all nursing students. For these reasons, innovative approaches are needed to teach oncology nursing practices (Freed and McLaughlin 2013; Rieger and Chernomas 2013). The use of innovative methods in the teaching and learning process of nursing practice and the active involvement of students in this process are very useful in terms of gaining different perspectives toward a subject. As a result, students may become better equipped, such as providing holistic care, making clinical decisions in complex and complicated cases, and acquiring the right, timely and ethical decision-making skills (Brandon and All, 20I0; Heimann et al., 20I3; Aliakbari et al., 2015). It has been stated that the constructivist approach from innovative learning approaches can be used in nursing education, but there is a limited number of studies in the literature regarding this subject. The aim of this research is to determine the effects of constructivist learning model on students' cancer nursing knowledge levels and problem solving skills.

\section{MATERIALS AND METHODS}

\section{Study population and design}

This research was conducted to determine the effects of activities based on the constructivist learning approach on the knowledge levels of cancer, cancer nursing 
functions and problem solving skills. In the research, a quasi-empirical research pattern was used in the form of pretest-posttest with control group. The second-grade nursing department students, who had oncology nursing lessons, were included in the study. The research universe was constituted by the second-grade nursing department students, who were studying in the 2017-2018 academic year in the university, where the research was conducted $(\mathrm{N}=130)$. Factors that may affect oncology nursing knowledge test scores are defined as exclusion criteria (students that previously undertook a cancer nursing course, having a first degree, relatives who received cancer diagnosis, that took the course for a second time, that graduated from health college). Ninety-six students were included in the research sample, with the exclusion of nine students having relatives with cancer history, 20 students who did not attend classes on the day oncology nursing was studied, and five students who graduated from a health college. How the students are assigned to groups was determined by an independent researcher who assigned the students to the groups by dividing the list into three according to student numbers. All students were included in the study and 32 students were planned to be in each group. However, since a limited number of students were admitted to the oncology clinic, the clinical practice group was limited to 22 students; one student who did not completely attend the constructivist learning approach oriented activities, one student absent from the oncology nursing clinical

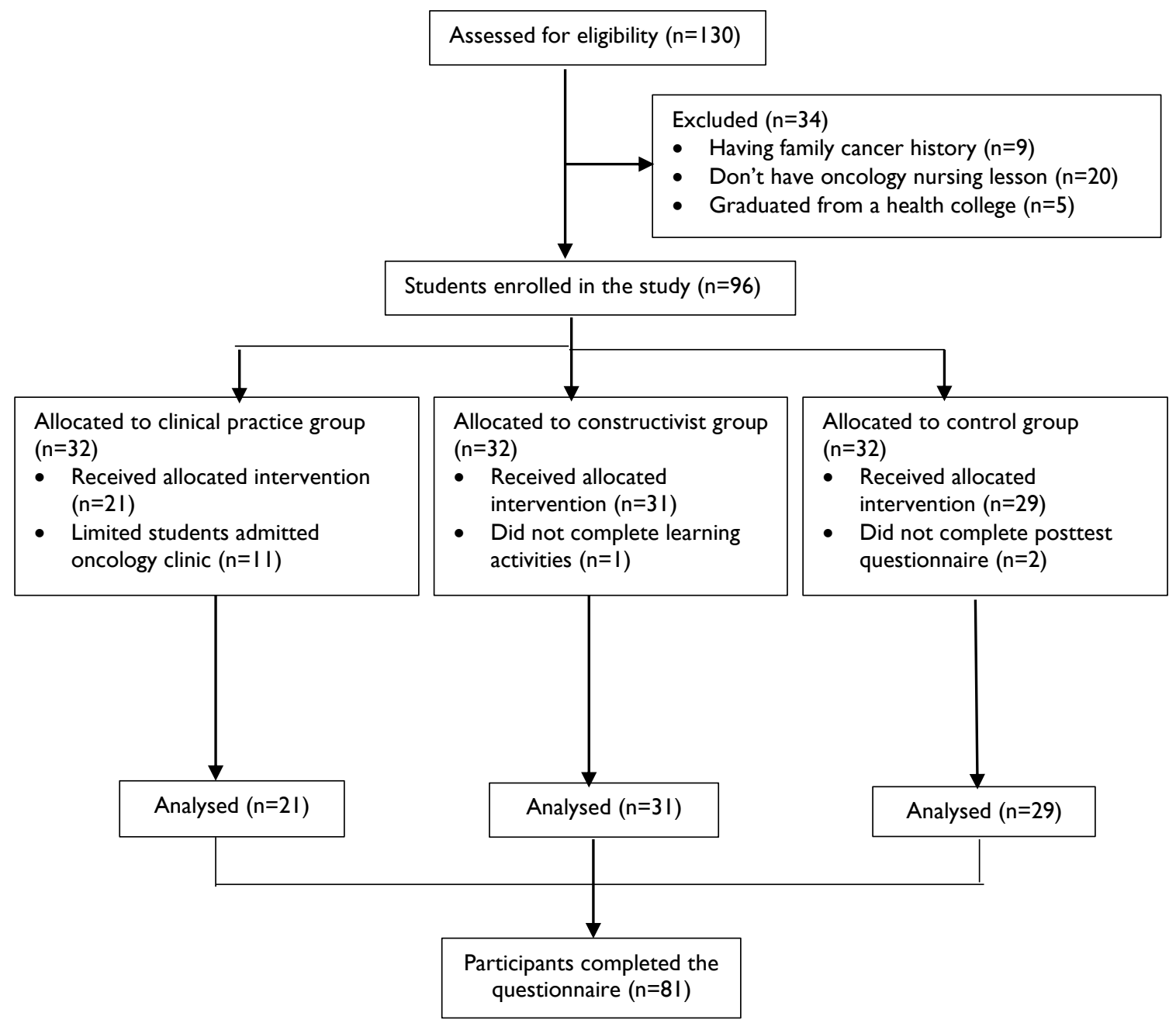

Figure I. The flow chart of the study 
practice, and three students having incomplete posttest questionnaire were excluded from the study. A total of 81 students completed the research, with $3 \mathrm{I}$ students in the constructivist approach group, 21 students in the clinical practice group, and 29 students in the control group (Figure I).

\section{Interventions}

As the application subject, within the scope of the Internal Medicine Nursing course, Oncology Nursing sub-field was selected. Eight hours of academic/theoretical lectures were given to the students by the specialist researcher, who had experience of oncology and researches conducted with cancer patients and oncology nurses. Theoretical training covers the cancer process, cancer types, cancer prevention, early diagnosis, cancer treatments (chemotherapy, radiotherapy, bone marrow transplantation, target therapies) and cancer nursing functions. In the lectures, direct instruction method was used. At the end of the course, written materials prepared for cancer and cancer nursing were given to the students.

Cancer nursing knowledge test and problem solving inventory was applied to measure pre-knowledge of students before theoretical lectures. Then, the students who fit the sampling criteria were divided into three groups as constructivist approach, clinical practice and control group. Cancer nursing knowledge test and problem solving inventory were reapplied so that the change of the knowledge level of the students could be determined after four weeks of application process.

\section{Constructive Approach Group}

Constructivist learning-based teaching approach about oncology nursing was applied to students in this group. Four themes (cancer problems and epidemiology in Turkey; cancer prevention and cancer treatment; oncology nursing activities and sample case presentation) were determined for the constructivist approach practices. The subjects were selected from a comprehensive review of the literature on oncology nursing. Students were asked to present these themes after the preparation period. The students planned and practiced activities related to cancer and cancer nursing functions for four weeks after the preliminary process. The students used various methods (visual presentation, role playing, posters, educational materials, videos, interviews) to present the themes. Using methods such as question-answer, discussion and demonstration, active participation of all students was ensured and formation of discussion groups was ensured. Activities were held for two hours two days a week for four weeks.

Activities were prepared and presented in accordance with the $5 \mathrm{E}$ model (engage, explore, explain, elaborate, evaluate) Engage: At this stage, four themes on oncology were given to the students by the educator. In the preparations regarding the subject, they were told to plan the activities such as sample case review, diagnose the problem, discussion, etc. The educator asked questions by presenting the importance of the subject (cancer problem in our country, importance of early diagnosis and cancer patients) and drew the students' attention to the subject. Explore: Students prepared the materials for each subject, to present with their own comments. During this process, videos, interviews, presentations, educational materials, brochures, and public spots were used. Explain: Students presented their presentations in the classroom, then, the educator made their own scientific explanations. The instructor clarified important concepts about oncology by asking questions to the whole group. Elaborate: At this stage, the students, who presented their own approaches and preparations, discussed the issues with group discussions. Interaction technique was used between student groups. Evaluate: Students were asked to analyze this case by giving a real oncology case example. Concepts related to oncology through history, diagnosis and treatment process and oncology nursing approaches, care plans and educational practices were evaluated.

\section{Clinical Practice Group}

The students in the clinical practice group performed clinical practices in the oncology clinics two days a week for four weeks. Clinical practice time was eight hours. Students in this group experiencing the experiential learning process took part in the patient/family education and the process by participating in 
the patient evaluation, treatment and care together with the oncology clinic nurses. Students also participated as observers in the chemotherapy units during the clinical practice process.

\section{Control Group}

Students in the control group only participated in the eight-hour theoretical lecture (cancer epidemiology, cancer types, cancer prevention, early diagnosis, cancer treatments, and cancer nursing functions) in which all students in the whole group participated. The students in this group walked to wards for practice in the areas within internal medicine nursing clinical practice other than the oncology clinic. They did not participate in any clinical practice/activity related to cancer and cancer nursing functions.

\section{Measures}

Research data were collected using the Descriptive Information Form, the Oncology Nursing Knowledge Test, and the Problem Solving Inventory. Pretests (descriptive information form, knowledge test and problem solving inventory) were applied to the students before the application. After the application, posttests (knowledge test and problem-solving inventory) were applied.

Cancer Nursing Knowledge Test consists of 20 questions. The total score obtained from the test is 100 . In order to ensure the content validity of the knowledge test, questions were included on each subject lectured within the eight-hour theoretical course attended by all students. Clear and concise words were used as much as possible in the questions. In the direction of the feedbacks obtained from the experts, the necessary corrections were made on the questions in the trial form and they were finalized. The content validity of the test was confirmed by experienced specialist academicians. There were questions about cancer nursing included in the test (Cancer epidemiology (IOpts), cancer prevention and early diagnosis (IOpts), cancer treatments and side effects (40pts), cancer nursing functions (40 pts)) and 25 questions were prepared for validity and reliability of the cancer nursing knowledge test. According to the results of reliability analysis, five questions were excluded from the information test because they were not meaningful. The reliability coefficient was determined as 0.850 according to 25 questions.

The Problem Solving Inventory developed by Heppner and Petersen (1982) to measure problem solving skills is a six-point Likert type scale consisting of 35 items. Participants respond to the items between the range of "always act like this" (I) and "never act like this" (Bush, 2006). The 9th, 22nd and 29th items were excluded from the scoring and the Ist, 2nd, 3rd, 4th, IIth, 13th, 14th, 15th, 17th, 21 st, 25th, 26th, 30th and 34th items were scored in reverse. Turkish validity and reliability study of the scale was implemented by Șahin et al. (1993). The total score from the inventory is between 32 and 192. The high total score of the scale indicates that the individual perceives himself/herself as inadequate in problem solving skills. In the scoring of the subscales, it was evaluated that the relevant approach forms were used more frequently, as the scores obtained from the subscales (thinking approach, self-confident approach, evaluative approach, and planned approach) that measured positive problem solving approach forms and in the scoring of subscales decreased, while it was considered that the relevant approach forms were used less, as the scores obtained from the subscales (hasty approach and avoidant approach) that measure positive problem solving approach forms decreased (Șahin et al., 1993).

\section{Data Analysis}

Demographic variables for students were reported as frequencies and percentages. Continuous variables were reported as mean \pm standard deviation. The Kruskal Wallis test was used when the differences between the test scores of the knowledge test and problem solving skills of the groups were examined because of the lack of parametric test assumptions. The Wilcoxon Sign test was used to compare the difference between the knowledge test scores of the constructivist approach group, the clinical experience group, the control group, and the problem solving sub-steps the pretest and posttest scores. Significance level was taken as $P<0.05$. Statistical analysis was performed in IBM SPSS for Windows Version 22.0 package program. 
Ethical committee approval (date: 10.05.2017/568) and institutional permission were taken by Ankara Yıldırım Beyazit University Ethics Committee. The students who would be included in the research were informed about the purpose and the application steps of the study and the approvals were received. The research was carried out in accordance with the Helsinki Declaration Principles. Written consents of students were obtained.

\section{RESULTS}

Table I. Characteristics of students $(n=8 I)$

\begin{tabular}{lllll}
\hline \multicolumn{1}{c}{ Characteristics } & \multicolumn{1}{c}{$\begin{array}{c}\text { Constructive } \\
\text { Mean } \pm \text { SD, } \mathbf{n}(\%)\end{array}$} & $\begin{array}{c}\text { Clinical practice } \\
\text { Mean } \pm \text { SD, } \mathbf{n} \\
(\%)\end{array}$ & $\begin{array}{c}\text { Control } \\
\text { Mean } \pm \text { SD, } \mathbf{n} \\
(\%)\end{array}$ & p \\
\hline $\begin{array}{l}\text { Age (years) } \\
\begin{array}{l}\text { Gender } \\
\quad \text { Female }\end{array}\end{array}$ & $20.57 \pm 9.36$ & $21.05 \pm 3.49$ & $20.15 \pm 7.86$ & 0.85 \\
$\quad$ Male & $23(74.2)$ & $20(69)$ & $17(81)$ & 0.78 \\
$\begin{array}{l}\text { Family } \\
\quad \text { Core family }\end{array}$ & $8(25.8)$ & $9(31)$ & $4(19)$ & \\
$\quad$ Extended family & $25(80.6)$ & $21(72.4)$ & $18(85.7)$ & 0.86 \\
\hline
\end{tabular}

Table 2. Comparison of the groups in terms results of the cancer nursing knowledge test

\begin{tabular}{|c|c|c|c|c|c|}
\hline \multirow[b]{2}{*}{ Groups } & \multicolumn{5}{|c|}{ Cancer nursing knowledge test } \\
\hline & $\begin{array}{c}\text { Pre-test } \\
\text { Median (min-max) }\end{array}$ & $\begin{array}{c}\text { Post- test } \\
\text { Median (min-max) }\end{array}$ & Difference & $\mathbf{Z}$ & $\mathbf{p}^{\mathbf{a}}$ \\
\hline Constructive methods & $29(16-41)$ & $53(35-72)$ & $27(-3-41)$ & -4.84 & $\leq 0.001$ \\
\hline Clinical practice & $24(8-40)$ & $45(26-61)$ & $20(-2-47)$ & -3.89 & $\leq 0.001$ \\
\hline Control & $27(10-37)$ & $39(26-50)$ & $12(-2-33)$ & -4.60 & $\leq 0.001$ \\
\hline KW & 4.79 & 32.26 & 16.64 & & \\
\hline $\mathrm{p}$ & 0.091 & $\leq 0.001$ & $\leq 0.001$ & & \\
\hline
\end{tabular}

Table 3. Comparison of the groups in terms results of the problem solving skills

\begin{tabular}{|c|c|c|c|c|c|}
\hline \multirow[b]{2}{*}{ Groups } & \multicolumn{5}{|c|}{ Problem solving inventory } \\
\hline & $\begin{array}{c}\text { Pre- test } \\
\text { Median(min-max) }\end{array}$ & $\begin{array}{c}\text { Post- test } \\
\text { Median(min-max) }\end{array}$ & Difference & $\mathbf{Z}$ & $\mathbf{p}^{\mathbf{a}}$ \\
\hline Constructive methods & $97(49-130)$ & $84(43-129)$ & $-9(-65-39)$ & -2.07 & 0.038 \\
\hline Clinical practice & $93(48-126)$ & $87(55-149)$ & $-8(-57-82)$ & -0.40 & 0.68 \\
\hline Control & $90(53-140)$ & $85(52-130)$ & $-5(-53-55)$ & -1.96 & 0.50 \\
\hline KW & 0.336 & 1.825 & 1.517 & & \\
\hline $\mathrm{p}$ & 0.845 & 0.402 & 0.466 & & \\
\hline
\end{tabular}

$\mathrm{p}^{\mathrm{a}} \quad$ : Wilcoxon Sign Test

KW :Kruskal Wallis 
significantly in all groups $(P<0.00 I)$. A significant difference was found between the knowledge pretest scores and posttest scores of the students in the constructive method group $(Z=-4.84 ; p \leq 0.00 I)$. There was a significant difference between the knowledge pretest and posttest scores of the students in the clinical practice group in favor of posttest scores $(Z=-3.89 ; p \leq 0.00 I)$. There was a significant difference between the knowledge pretest and posttest scores of the students in the control group in favor of the posttest scores. ( $Z=-4.60 ; p \leq 0.00 I)$. There was a statistically significant difference in the posttest scores of the groups $(\mathrm{KW}=4.79 ; \mathrm{p} \leq 0.00 \mathrm{I})$ When the knowledge test scores between the groups were examined, the constructivist approach group had higher knowledge test scores than control group. There was no difference in their knowledge test results between constructivist approach and clinical practice $(p \leq 0.05)$.

Table 3 shows comparative results of pretest-posttest scores for problem solving skills of groups. It was determined that the constructivist approach group's evaluative approach scores were higher than the control group $(p<0.05)$. The problem solving skills of the students in the constructive method group were found to be significantly different between the posttest scores ( $Z=-2.07$; $\mathrm{p} \leq 0.05)$. There was no statistically significant difference in the problem solving posttest scores of the groups ( $K W=0.33 ; p \geq 0.05)$.

A quasi-experimental design with pretestposttest control group design was used in the study. These data are confined to only the subsequent four weeks of constructivist learning. Further work is needed to develop larger cases and in different time settings.

\section{DISCUSSIONS}

Cancer nursing is one of the specialty nursing fields that require expertise and experience. Essential information explained throughout the resource diversity in teaching oncology nursing applications to students should be taught by questioning and examining for its reasons one-by-one, from a critical perspective. In a study comparing the $5 \mathrm{E}$ (engage, explore, explain, elaborate, evaluate) learning model with the traditional lesson planning instruction, it was found that the students receiving the course with the $5 \mathrm{E}$ learning model achieved high academic achievement (Gutierrez, 2006). Hwang (20I8) compared the effectiveness of problem based learning with the traditional course-based learning in enhancing cancer awareness, and problem-based learning was found to be an effective method to increase cancer awareness and self-managed learning in undergraduate students in areas other than health (Hwang, 2018). Van der Wath and Du Toit (20I5) found that the use of constructivist education model in nursing students increased the sensual and emotional awareness of students about death and dying (Van der Wath and DuToit, 2015). Choe et al. (2014) reported that the students in both the action learning and constructivist approach groups improved their ethical competence after bioethics training (Choe et al., 20l4). In our study, the constructivist approach group was found to have higher knowledge test scores than the control group. It is thought that different teaching techniques can contribute to the enhancement of student knowledge and skills by integrating it into nursing education.

In a constructivist approach, critical thinking, questioning, problem solving and entrepreneurship of the individual are featured (Brooks, and Brooks, 1999). In this approach, there are many teaching techniques such as group discussions among students, projectbased learning, and problem solving-based learning. In our study, evaluative approach and total scale scores of constructivist approach were found to be higher than control group. Similarly to our study, Ançel (20I6) found that students who received problem solving education had a statistically significant change in the 'thinking approach', 'evaluative approach' and 'planned approach' subscale scores and that students perceived themselves more competent (Ançel, 2016). Kanbay and Okan (2017) determined that the overall problem solving skills of students who received critical thinking education were higher (Kanbay and Okanlı, 2017). In a study on the problem solving skills of pre-service teachers based on constructivist learning, it was found that there was a significant difference between the posttest results of the experimental and control groups (Kaya and Karakaya, 20I2) 


\section{CONCLUSION}

As a result of the research, it was determined that active learning approaches positively affect nursing students' understanding of oncology nursing practices. Research findings can contribute to nursing education, practice and research, and are important for strengthening awareness and knowledge of oncology nursing. The research findings help to understand how the students' learning experiences and perceived competencies contribute to awareness of oncology nursing. Interactive teaching methods will make a positive contribution to learning oncologic patient care. Students will not feel unprepared when they start working and provide adequate care. The positive effects of experiential learning and constructivist learning, which are applied as teaching strategies to understand oncology nursing issues, are determined. In the future, it is recommended to carry out further educational software development and research to increase the learning efficiency of nursing education. It is suggested that the education given to the nursing students should be reviewed in terms of the theories and changes that improve the constructivist approach activities should be made in the nursing education process. The use of constructivist educational approaches in nursing education and the necessary arrangements for clinical and theoretical applications should be recommended.

\section{Acknowledgement}

We would like to thank the participants who have helped in this research and the research sites that have facilitated this research.

\section{Conflict of Interest}

All the authors have no conflict of interest related to the study.

\section{REFERENCES}

Aliakbari, F., Parvin, N., Heidari, M., Haghani, F. (20I5). Learning theories application in nursing education. J Educ Health Promot, 4 (2). 9531.151867

Ançel, G. (20I6). Problem-solving training: effects on the problem-solving skills and self-efficacy of nursing students. Eurasian Journal of Educational Research, 64, 231246.

http://dx.doi.org//0.14689/ejer.2016.64.I 3.

Bahrami, M. (2010). Do nurses provide holistic care to cancer patients? Iran J Nurs Midwifery Res, 15(4), 245-25।.

Bush, G. (2006). Learning about literacy: From theories to trends. Teacher Librarian, 34, 14-18.

Brandon, A.F., All, A.C. (20I0). Constructivism theory analysis and application to curricula. Nursing Education Perspectives, 3I, 2, 89-92.

Brooks, M.G, Brooks, G. J. (1999). The courage to be constructivist. Educational Leadership, 57 (3), I8-24.

Choe, K., Park, S., Yoo, S.Y. (20I4). Effects of constructivist teaching methods on bioethics education for nursing students: a quasi-experimental study. Nurse Educ Today, 34(5), 848-53. https://doi.org/ 10.1016/j.nedt.2013

Freed, P.E., McLaughlin, D.E. (20I3). Promoting cultures of thinking: Transforming nursing education to transform nursing practice. Creative Nursing, 19(4), 174-181.

Gill, F., Duffy, A. (20/0). Caring for cancer patients on nonspecialist wards. British Journal of Nursing, 19(12), 76I-767. https://doi.org/I0.12968/bjon.2010.19.12. 48654

Gutierrez, F.M. (2006). Faculty best practices using blended learning in e-learning and face to face instruction. International Journal on E-Learning, 5 (3), 3I 3-337.

Hawk, T.F, Shah, A.J. (2007). Using learning style instruments toenhancestudent learning. Decision sciences. Journal of Innovative Education, 5(I), I-19. https://doi.org//0.1 I I I/j.15404609.2007.00I25.x

Heimann, C., Prado, C., de Moraes, R.R., Vidal, G.V., Liberal, D., Oliveira, GK., Barata, M.V. (20I3). Acquiring nursing knowledge through the constructivist method. Rev Esc Enferm USP, 47(4), 992-5. 
https://doi.org/ 10.1590/S0080623420130000400032

Hwang, L.L. (20I8). Educational intervention on undergraduate cancer awareness and self-directed learning. J Cancer Educ, 33, 592-60I. https://doi.org/ 10.1007/s I3187$017-1210-y$.

Kanbay, Y., Okanlı, A. (2017). The effect of critical thinking education on nursing students' problem-solving skills. Contemp Nurse., $\quad$ 53(3), 313-321. https://doi.org//0.1080/10376I78.2017.13 39567

Komprood, S.R. (2013). Nursing student attitudes toward oncology nursing: An evidence based literatüre review. Clin J Oncol Nurs., 17(I), 2I-28. http://doi.org/I0.I I 88/I3.CJON.E2 I-E28

Rieger, K.L., Chernomas, W.M. (20I3). Artsbased learning: Analysis of the concept for nursing. International Journal of Nursing Education Scholarship, 10(34): 1-10. http://doi.org//0.15/5/ijnes-2012-0034.
Rieger, P.T., Yarbro, C.H. (2003). Role of the oncology nurse. In: Kufe DW, Pollock RE, Weichselbaum RR, Bast RC, Gansler TS, Holland JF, et al. editors. Holland-Frei Cancer Medicine. 6th ed. Shelton, CT: People's Medical Publishing House

Șahin, N., Șahin, N.H., Heppner, P.P. (1993). Psychometric properties of the problem solving inventory in a group of turkish university students. Cognit Ther Res, 17, 379-396.

Quinn, A. (2008). Expandingthe role of the oncology nurse. Biomed Imaging Interv J, 4(3). 10.2349/biij.4.3.e34

Van der Wath, A.E., DuToit, P.H. (20I5). Learning end-of-life carewithin a constructivist model: Undergraduate nursing students' experiences. Curationis, 38 ,

2. http://dx.doi.org/10.4102/curationis.v38i2. 1537 